\title{
Editorial
}

\section{Rup Pur: Harnessing The World's Most Concentrated Energy Source}

\section{Dr. Md Zahirul Haque ${ }^{1}$}

As Bangladesh is entering into the era of nuclear power, there has been a strong awareness of the potential hazard of both nuclear criticality and release of radioactive materials from generating electricity with nuclear power.

No industry is immune from accidents, but all industries learn from them. As in other industries, the design and operation of nuclear power plants aims to minimize the likelihood of accidents, and avoid major human consequences when they occur.

There have been three major reactor accidents in the history of civil nuclear power - Three Mile Island, Chernobyl and Fukushima. One was contained without harm to anyone, the next involved an intense fire without provision for containment, and the third severely tested the containment, allowing some release of radioactivity.

These are the only major accidents to have occurred in over 17,000 cumulative reactor-years of commercial nuclear power operation in 33 countries.

The evidence over six decades shows that nuclear power is a safe means of generating electricity. The risk of accidents in nuclear power plants is low and declining. The consequences of an accident or terrorist attack are minimal compared with other commonly accepted risks. Radiological effects on people of any radioactive releases can be avoided.

In the UK, Friends of the Earth commissioned a study by the Tyndall Centre, which drew primarily on peer-reviewed academic literature, supplemented by literature from credible government, consultancy and policy sources. It concluded in January 2013 that "Overall the safety risks associated with nuclear power appear to be more in line with lifecycle impacts from renewable energy technologies, and significantly lower than for coal and natural gas supplied energy."

While preventing nuclear accident is the real solution, we must have plans in place for any emergency situations.

Clear plans from local authorities are needed for any protective measures that can happen as a result of a radiological incident. For example, Potassium Iodide (KI) can protect the thyroid from radiation damage. In case of a radiological event, infants (including breastfed infants), children under 18 years of age, young adults between the ages of 18 to 40 years of age, pregnant women, and breastfeeding woman are recommended to take KI. 